\title{
Numerical study concerning the influence of contact ratio at helical involute gears
}

\author{
Sorin Gabroveanu ${ }^{1, *}$, Sorin Cananau ${ }^{2}$, and Radu-Florin Mirica ${ }^{2}$ \\ ${ }^{1}$ Institutul National de Cercetare-Dezvoltare Turbomotoare COMOTI, Bucuresti, Romania \\ ${ }^{2}$ Universitatea "POLITEHNICA", Bucuresti, Romania
}

\begin{abstract}
In the present paper some aspects of the influence of the overlap ratio of the gear set on its dynamic comportment was studied. In this aim, the values of angular acceleration of two helical involute gear sets having the same characteristics - excepting the face width - are determined. The study is performed using a software in the category of The Multibody Dynamics Simulation Solution for simulation the dynamic comportment for various width of the driven gear, at various torques and various angular velocities.
\end{abstract}

\section{Introduction}

The noise generated by a working gear pair is related to the vibration of elements in running conditions. The cause is the gear mesh stiffness variations. There are a lot of scientists involved in studying this problem. V.K. Tamminana etalt. [1] studied the relationship between the dynamic factors and the dynamic transmission error of spur gear pairs; Inoue et al. [2] studied the vibration energy due to the functioning of the shafts and rolling bearings; E. Tanaka atalt.[3] studied the vibration and sound-radiation analysis for designing a low-noise gearbox with a multi-stage helical gear system. If the designers of gears set assure that the fluctuation in the gear mesh stiffness are significantly reduced, it is expected that the vibration, dynamic overload and total transmission error are also reduced [4]. The overlap ratio depends of the face width of the gear, but the contact ratio remains independent from this one. Usually the face width is a subject of the gear set design, design restrictions, load level and others. In the present paper we will study the influence of the width of the gear set on the vibration level.

\section{Theoretical considerations}

For a smooth meshing in the case of helical gears there is a transition of tooth contact from one pair in contact to the next one. In other words there must be at least one point of contact in the surface of action. Due to strength conditions of work in the case of helical gears a further requirement of mating gears and this requirement said that all points of contact along the minimum required path of contact should be, by each corresponding point, in contact along the meshing line over the face width. In Fig. 1 is shown the meshing along the contact line and the relation with the contact ratio parameter for a helical gear. For quantifying the meshing conditions, the contact ratios as geometrical parameters are used.

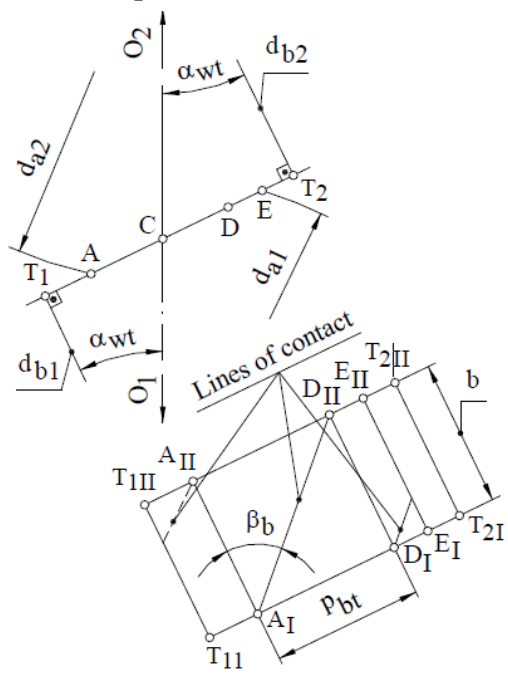

Fig. 1. The gear meshing with axial contact ratio equal to unit with $A_{I} A_{I I} E_{I I} E_{I}$ - plan of action (after [5]).

This main geometrical parameter is transverse contact ratio, $\varepsilon_{\alpha}$, that greater as unit must be:

$$
\varepsilon_{\alpha}=\frac{\text { path of contact }}{\text { base pitch }}=\frac{\mathrm{AE}}{\mathrm{p}_{\mathrm{bt}}}
$$

For a numerical expression we can compute:

$$
\varepsilon_{\alpha}=\left[z_{1} \operatorname{tg} \alpha_{a t 1}+z_{2} \operatorname{tg} \alpha_{a t 2}-\left(z_{1}+z_{2}\right) \operatorname{tg} \alpha_{w t}\right] / 2 \pi
$$

with $z_{1}$ and $z_{2}$ - teeth numbers, $\alpha_{\text {at1 }}$ and $\alpha_{\mathrm{at} 2}$ - pressure angles at teeth tips, $\alpha_{\mathrm{wt}}$ - pressure angle at the pitch cylinder. 
The overlap ratio $\varepsilon_{\beta}$ of a helical gear set - as a second geometrical parameter - is the quotient of the face width (b) divided by the axial pitch $\left(\mathrm{p}_{\mathrm{a}}\right)$ :

$$
\varepsilon_{\beta}=\frac{b}{p_{a}}=\frac{b \cdot \sin \beta}{\pi \cdot m_{n}}
$$

with $\beta$ - helix angle; $\mathrm{m}_{\mathrm{n}}$ - normal module.

The total contact ratio $\varepsilon_{\gamma}$ of a gear pair is equal to the sum of both. In this conditions for helical gears must be fulfilled the condition from following expression:

$$
e_{\gamma}=e_{\mathrm{x}}+\varepsilon_{\beta}>1
$$

In this paper some results of a numerical study on the influence of overlap ratio $\varepsilon_{\beta}$ on the dynamic comportment of the gears.

\section{Model and simulation}

Two gear sets having different overlap ratio are numerically studied. The modelled gear sets are the same data, but differ theirs face width. To carry out the models are used the data of a real gear set, as is shown in Fig.2.

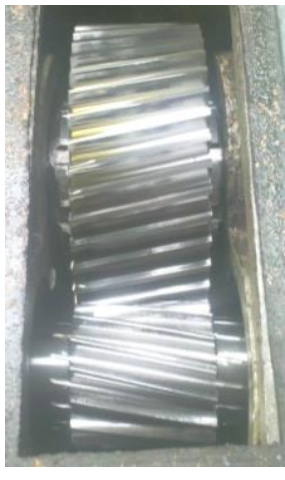

(a)

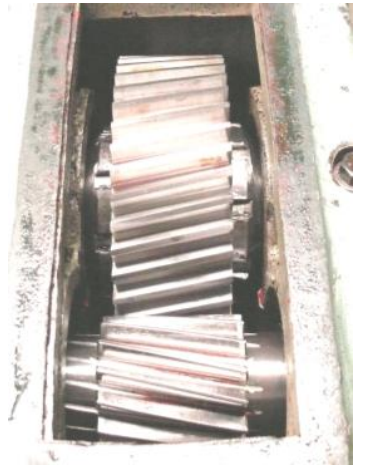

(b)
Fig. 2. The gear set with the overlap ratio equal to unit (a) and reduced one (b).

The characteristic data of gear sets are given in the Table 1. For modifying the overlap ratio of the modelled gear sets, the face with was changed.

Table 1. Geometrical parameters of the set model.

\begin{tabular}{|c|c|c|}
\hline \multicolumn{2}{|c|}{ Geometrical parameter } & Value \\
\hline Work centre distance & $a_{w}$ & $125 \mathrm{~mm}$ \\
\hline Number of teeth (driving gear) & $z_{1}$ & 15 \\
\hline Number of teeth (driven gear) & $z_{2}$ & 46 \\
\hline Helix angle & $\beta$ & $10^{\circ}$ \\
\hline Profile shift coefficient (driving gear) & $x_{1}$ & 0.427 \\
\hline Profile shift coefficient (driven gear) & $x_{2}$ & -0.138 \\
\hline Transverse contact ratio & $\varepsilon_{\alpha}$ & 1.4532 \\
\hline Face width & $\mathrm{b}$ & $72.366 \mathrm{~mm}$ \\
\hline Overlap ratio & $\varepsilon_{\beta}$ & 1 \\
& & \\
\hline & & \\
\hline
\end{tabular}

For the gear set with the face width of $72.366 \mathrm{~mm}$ is obtained the overlap ratio equal to one and for the one having the face width of $68.367 \mathrm{~mm}$ results the overlap ratio of 0.867 .

For the achievement of numerical analysis of the influence of the face width on the dynamic comportment of modelled operating gear sets, at various speeds, the software ADAMS was used.

The both models of gear sets are virtually operated at pinion rotational speeds of $1000 \mathrm{rot} / \mathrm{min} 2000 \mathrm{rot} / \mathrm{min}$ and $3000 \mathrm{rot} / \mathrm{min}$ and torque values of $100 \mathrm{Nm}, 100 \mathrm{Nm}$, $200 \mathrm{Nm}$ and $300 \mathrm{Nm}$.

It is to observe that the operating simulation is impossible by unloaded gears. This is the reason of choosing of torque of $100 \mathrm{Nm}$.

In all these numerical experiments the angular velocity of driven wheel and its angular acceleration are computed.

\section{Results}

Some results of numerical simulations using the software ADAMS are given below.

As is shown in Fig. 3 and Fig.4, there is no important difference regarding the angular velocities (the red lines) of driven wheels of the modelled gear sets at 1000 $\mathrm{rot} / \mathrm{min}$ and the torque of $100 \mathrm{Nm}$.

Concerning the angular acceleration, this is greater by the narrow gear having the overlap ratio of 0.867 than the one of the gear set having the overlap ratio equal to one.

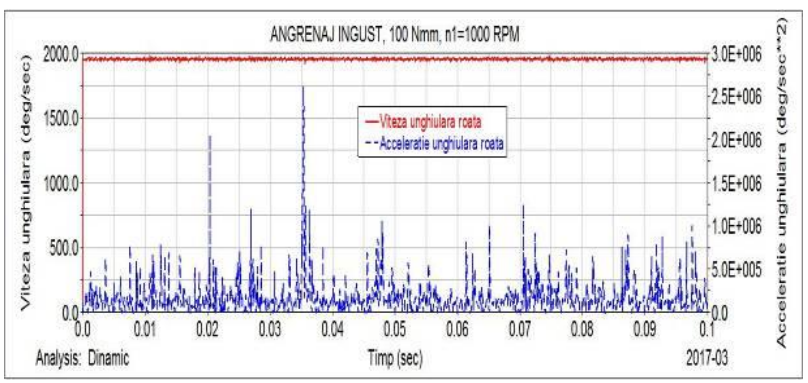

Fig. 3. Angular velocity (red line) and angular acceleration (blue line), at driven gear, at $\mathrm{T}=100 \mathrm{Nm}$, $\mathrm{n} 1=1000 \mathrm{rmp}$, narrow gear $\left(\varepsilon_{\beta}=0.867\right)$.

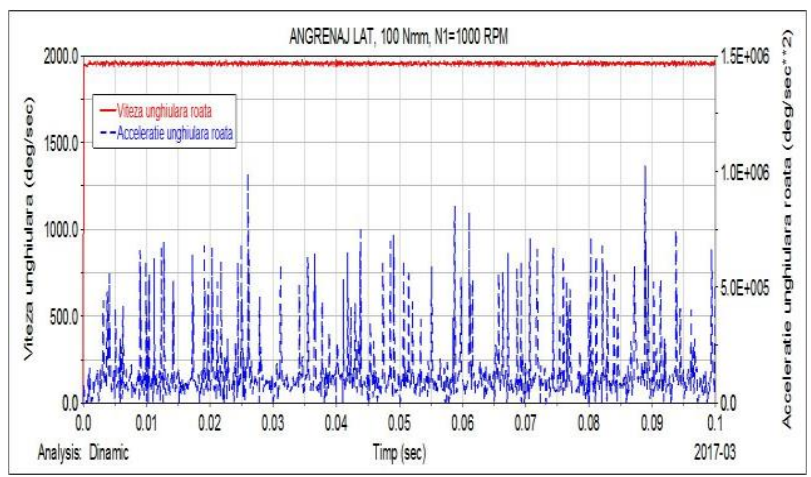

Fig. 4. Angular velocity (red line) and angular acceleration (blue line) of driven gear, at $\mathrm{T}=100 \mathrm{Nm}$, $\mathrm{n} 1=1000 \mathrm{rmp}$, wide gear $\left(\varepsilon_{\beta}=1\right)$. 
For a rotational speed of $2000 \mathrm{rot} / \mathrm{min}$ the angular velocity has small variations by modifying the torque, as is shown in the fig. 5 .

These variations are emphasised magnifying the scale of the diagram.

Concerning the angular acceleration, this one has lower levels at wide gear - having overlap ratio equal to one than at narrow gear with smaller value of overlap ratio. It is to observe the continuous increasing of angular acceleration with the loading torque.

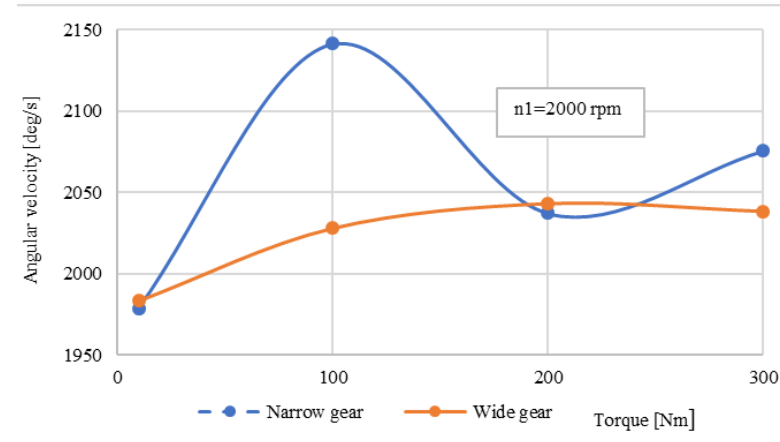

Fig. 5. Angular velocity at driven gear, $\mathrm{n} 1=2000 \mathrm{rot} / \mathrm{min}$ for various torques

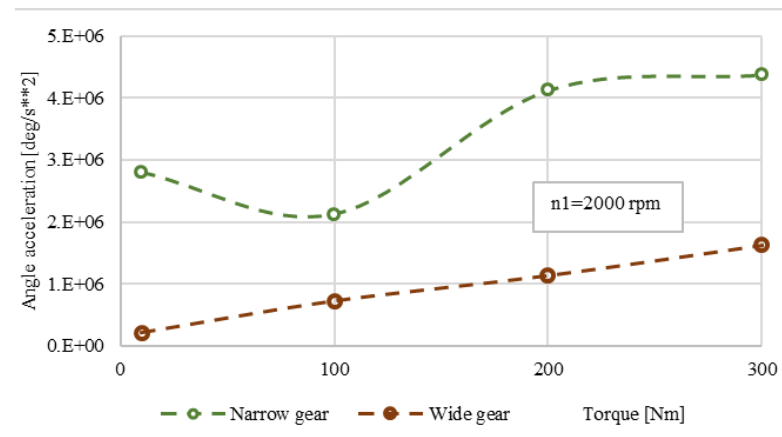

Fig. 6. Angular acceleration, at driven gear, $\mathrm{n} 1=2000 \mathrm{rot} / \mathrm{min}$, various torques

Increasing the rotational speed at $3000 \mathrm{rot} / \mathrm{min}$, the level of angular acceleration grows with the loading torque. In the fig. 7 appears the same tendency, as before, excepting of level at $100 \mathrm{Nm}$, where the angular acceleration of wide gear is higher than the one of narrow gear.

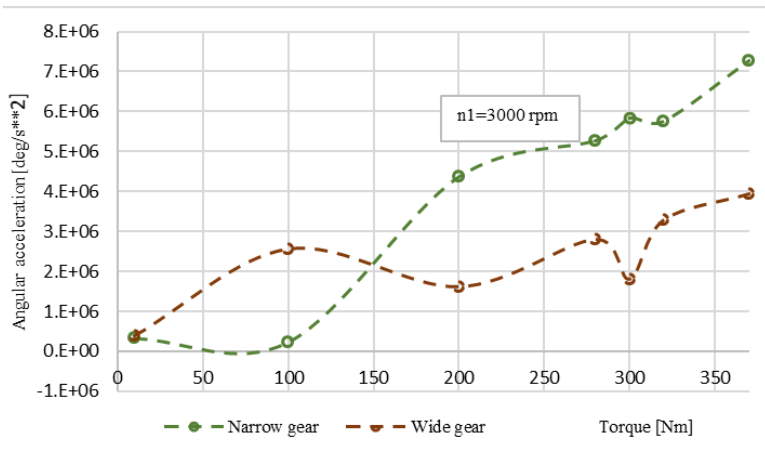

Fig. 7. Angular acceleration, at driven gear, $\mathrm{n} 1=3000 \mathrm{rot} / \mathrm{min}$, various torques.
The discontinuities of level variation of angular acceleration are caused probably by the model accuracy or other unconsidered influence factor.

Excepting the mentioned discontinuities, the level of angular acceleration is increasing with the loading torque for both gear sets.

The gear set having overlap ratio equal to one has lower levels of angular acceleration than the one with overlap ratio unequal to one.

\section{Conclusions}

We can consider that for a gear set with overlap ratio equal to an integer number (in our case study equal to unit), the dynamic comportment is better than in the case of a gear set without integer overlap ratio.

Increasing the load (the torque applied at the pinion) the angular acceleration of driven wheel grows slowly in the case of gear set having overlap ratio a natural number than in the case of different one.

\section{References}

1. V.K. Tamminana, A. Kahraman, S. Vijayakar, A study of the relationship between the dynamic factors and the dynamic transmission error of spur gear pairs, J. Mech. Des. 129 (1) (2007) 75-84

2. K. Inoue , D.P. Townsend , J.J. Coy , Optimum design of a gearbox for low vibration, J. Mech. Des. 115 (4) (1993) $1002-1007$

3. E. Tanaka, H. Houjoh, D. Mutoh , H. Motoshiromizu , K. Ohno , N. Tanaka , Vibration and sound-radiation analysis for designing a lownoise gearbox with a multi-stage helical gear system, JSME Int. J. Ser. C Mech. Syst. Mach. Elem.Manuf. 46 (3) (2003) 1178-1185

4. T. Sato , K. Umezawa , J. Ishikawa, Effects of contact ratio and profile correction on gear rotational vibration, Bull. JSME 26 (221) (1983) 2010-2016

5. G. Dobre, R.Mirica, S.Gabroveanu, The reduction of the gear parametrical excitations, with application in aeronautics, Conferinta Internationala de Stiinte Aerospatiale "AEROSPATIAL 2008", Bucuresti, 1-2 Octombrie 2008 - Sectiunea 2.pp 12-13 